\title{
In-vitro selection of drought tolerant peanut embryogenic calli on medium containing polyethylene glycol and regeneration of drought tolerant plants
}

\author{
Enni Suwarsi Rahayu'1,2, S. Sudarsono ${ }^{2^{*}}$ \\ ${ }^{1}$ Department of Biology, Faculty of Mathematics and Science, Semarang State University (Unnes), Semarang 50229, Indonesia; ${ }^{2}$ Plant \\ Molecular Biology Laboratory, Department of Agronomy and Horticulture, Faculty of Agriculture, Bogor Agricultural University (IPB), JI. Meranti, \\ Darmaga Campus, Bogor 16680, Indonesia
}

\section{A B S T R A C T}

\begin{abstract}
Negative impact of drought stress has been recognized to pose a growing threat to sustainable agriculture particularly under the global climate change. The main goal of this research was to develop an effective protocol for regenerating drought tolerant peanut plants. Specific objectives were to select drought tolerant embryogenic calli (EC), on a medium containing polyethylene glycol (PEG), and evaluate the regenerated lines against drought stress environment. Somaclones were selected through continuous culture of EC for 6 months on MS-P16 medium. The EC were sub-cultured onto the fresh MS-P16 medium every month. In vitro drought tolerant somatic embryos (SE) were selected on MS-P16 medium containing 15\% PEG 6000. PEG tolerant SEs were regenerated (RO plantlets) and grown to maturity in the greenhouse to produce R1 seeds. Subsequently, these seeds were planted to maturity to produce R2 seeds. The R2 plants were subjected to drought stress by reduced watering under greenhouse conditions and their growth parameters and yield were recorded. Results showed plants regenerated from 6-month-old EC cultures exhibited variations in plant height, fresh and dry weight of above ground biomass and of the roots, total pod and filled (matured) pod yield at harvest. The majority (56-100\%) of the EC did not survive the in-vitro selection on MS-P16 containing 15\% PEG. However, some newly regenerated SEs developed from mostly browning tissues on the same medium. Peanut plants were regenerated from these SEs and the R1 and R2 plants derived from these somatic embryos were obtained. Among evaluated R2 plants regenerated from PEG stress tolerant SEs, $44 \%$ plants exhibited drought tolerance under greenhouse conditions.
\end{abstract}

Keywords: Drought stress; Dehydration stress; PEG stress tolerance; Somatic embryo; Somaclonal variant; Arachis hypogaea

\section{INTRODUCTION}

Global warming threatens traditional farming in many different ways. The debated changes in climate pattern because of global warming could result in uncertainties of yearly rainy and dry seasons (Ceccarelli et al., 2010). To anticipate such potential problems, breeding and developing new crop varieties adapted to climate change is one of the important strategies for adapting agriculture to the changing environments. Increase in drought periods may require the development of drought tolerant crops (Ceccarelli et al., 2010; Ahmed et al., 2013).

Drought stress could cause a significant yield reduction in peanut (Arachis hypogaea L.). Total pods, seed yields and shelling percentages of peanut were reduced because of drought stress (Vorasoot et al., 2003; Shinde and Laware, 2010).

To prevent yield losses caused by drought stress, development of drought tolerant peanut cultivars is necessary. Under drought stress conditions, yield reduction of tolerant cultivars would theoretically be less than those of sensitive ones (Vorasoot et al., 2003; Shinde and Laware, 2010). Drought tolerant cultivars exhibited increase in proline biosynthetic enzyme activities in leaves under drought stress (Phutela et al., 2000; Barthakur et al., 2001); hence, increased in proline content in those organs. Proline functions as one of the osmo-protectants in plant cells under drought stress (Phutela et al., 2000; Farooq et al., 2009; Omidi, 2010; Rabert et al., 2014).

\footnotetext{
${ }^{*}$ Corresponding author:

S. Sudarsono, Plant Molecular Biology Laboratory, Department of Agronomy and Horticulture, Faculty of Agriculture, Bogor Agricultural University (IPB), JI. Meranti, Darmaga Campus, Bogor 16680, Indonesia. E-mail: s_sudarsono@ymail.com
} 
Major constrains in breeding for drought tolerant cultivars include limited availability of germplasm donor for the tolerant characters and the complexity of selection methods for the trait (Sinclair, 2011). When tested under drought stress similar to one used in this experiment, a number of supposely drought tolerant peanut cultivars in Indonesia were in fact either sensitive or medium tolerant and none of them were identified as drought tolerant based on their drought sensitivity index (Riduan et al., 2005). Hence, development of drought tolerant peanut cultivars are neccessary.

It has been widely accepted that applying drought stress during callus or plant cells proliferations is efficient for selecting drought tolerant cell lines and the regeneration of tolerant plants (Mohamed et al., 2000). Different responses for drought tolerance, such as a higher membrane stability and a better yield when grown under low water potential, have been identified from somaclonal variants (Matheka et al., 2008; Mohamed et al., 2000; Widoretno and Sudarsono, 2004; Mahmood et al., 2012a).

In vitro regenerated plants often exhibit phenotypic differences. Some of these differences may have been inherited in the progeny generations (Jain, 1997; Larkin, 1998) and are exploited for developing new germplasm with improved characters such as tolerance to abiotic stress (Jain, 2001). Somaclonal variation may be the results of a number of DNA changes (Cassells and Curry, 2001; Mujib et al., 2007) since some of the observed variation is heritable (Jain, 1997; Larkin, 1998).

In-vitro selection by culturing plant cells and tissues on medium supplemented with polyethylene glycol (PEG) or mannitol have identified drought tolerant tissues of potato and rice (Gopal and Iwama, 2007; Wani et al., 2010; Rai, 2011). As a selective agent to simulate drought stress, high molecular weight PEG (i.e. PEG 6000) (Rai, 2011), which is non-penetrative and able to induce drought stress similar to drought stress in the field (Steuter, 1981; Gawande et al., 2005). Successful selections for drought tolerance has been carried out in the presence of PEG in tomato (Abdel-Raheem et al., 2007), potato (Gopal and Iwama, 2007), maize (Matheka et al., 2008), banana (Bidabadi et al., 2012), wheat (Mahmood et al., 2012a) and soybean (Widoretno et al., 2003).

We have developed efficient procedures for inducing somatic embryos from peanut leaflet explants (Edy, 1998; Sulichantini, 1998). Our previous studies have also demonstrated the tolerant peanut embryogenic callus could survive in such selective medium supplemented with PEG and might regenerate into drought tolerant plantlets (Rahayu et al., 2005; Rahayu and Sudarsono, 2009a,b). The main goal of this study was to develop an effective protocol for regenerating drought tolerant peanut. Specific objectives are to regenerate somaclonal variants among embryogenic calli (EC), to select drought tolerant lines on a medium containing polyethylene glycol (PEG), to evaluate the regenerated lines against drought stress under greenhouse conditions, and to demonstrate that the tolerance is genetically controlled and transmitted from R0 plants to the next generation, the drought tolerance were evaluated at the R2 generation.

\section{MATERIALS AND METHODS}

\section{Plant material}

This experiment used three commercial peanut cultivars, Singa, Kelinci, and Badak. The cv. Badak is known to be more sensitive to drought stress in the field than the other two cultivars tested.

\section{PEG inhibitory concentration}

Mature peanut seeds were sterilized in $5 \% \mathrm{NaOCl}$ solution for 2-3 minutes and rinsed three times in sterile aquadest. To initiate EC and SE, leaflets were excised from embryo axis of sterilized mature peanut seeds and cultured on MS medium (Murashige and Skoog, 1962) supplemented with $16 \mu \mathrm{M}$ picloram (MS-P16 medium). The cultures were incubated under the dark until they initiate EC and SE. Peanut leaflets started initiating EC and SE after 10-12 weeks in MS-P16 medium. Continuous cultures of the explants on MS-P16 medium induced development of a mixture of EC and SEs (Edy, 1998; Sulichantini, 1998). The established EC and SEs of peanut were subsequently used to evaluate inhibitory effects of PEG.

The inhibitory effects of PEG 6000 at $0 \%, 5 \%, 10 \%, 15 \%$ or $25 \%$ concentrations in MS-P16 medium on growth and proliferation of EC and SEs were evaluated in a completely randomized design experiment. Each experimental unit consisted of five clumps of peanut EC cultured in one culture vial $(250 \mathrm{ml})$ containing $25 \mathrm{ml}$ of MS-P16 medium. Each clump of the EC contained 8 to 10 SEs. Five replicates were prepared for each of PEG concentration.

This study used liquid PEG-supplemented MS-P16 medium to proliferate peanut EC and SEs as agar would not solidify in the presence of a high concentration of PEG 6000. Sterilization of the media used standard heat sterilization methods at $120^{\circ} \mathrm{C}, 1,5 \mathrm{~kg} / \mathrm{cm}^{2}$ using autoclave. To prevent explants from drowning, a raft covered with a single layer of filter paper (Whatman, grade 6 filter paper) was floated on the liquid medium. Peanut EC and SE were laid on top of the filter and cultured on the medium for a total of three months period. The EC were transferred onto fresh medium every month. 
Percentages of EC and SEs survival and the number of proliferated SEs after three months on selective medium were recorded. The concentration of added PEG inhibiting at least $90 \%$ of the culture survival or SE proliferation relative to those of $0 \%$ PEG was determined.

\section{Regeneration of somaclonal variants}

These activities examined the somaclonal variants among regenerated plantlets from SEs without PEG treatment. The presence of somaclonal variants was evaluated by observing phenotype changes among regenerated plantlets compared to control plant grown from seeds. Both populations were maintained in the greenhouse.

The EC of peanut cv. 'Kelinci' were initiated as previously described (Edy, 1998; Sulichantini, 1998). As many as 200 clumps of peanut EC with 8 - 10 SEs per clump were used as explants. Five clumps of peanut EC were cultured on a single culture vial $(250 \mathrm{ml})$ containing $25 \mathrm{ml}$ solid MS-P16 medium. The explants were transferred onto fresh MS-P16 medium every month and continually proliferated for a six months period. At the end of six months, all EC were transferred onto MS medium supplemented with activated charcoal ( $2 \mathrm{~g} / \mathrm{l}$; MS-AC medium) for SE maturation and germination. Germinated SE was transferred onto MS medium supplemented with $22 \mu \mathrm{M}$ BAP (6-benzylamino purine) to regenerate shoots. The regenerated shoots $(2-3 \mathrm{~cm})$ were excised and transferred onto MS medium supplemented with $10 \mathrm{mg} / 1 \mathrm{NAA}$ for one week. Subsequently, the NAA treated shoots were transferred onto MS-AC medium for 3-4 weeks to induce rooting and regenerate plantlets. In all culture steps, the EC were incubated in culture room with a constant temperature of $25^{\circ} \mathrm{C}$ and a continuous lighting at approximately 900-940 lux (11.3-11.8 $\left.\mu \mathrm{e} \mathrm{m}^{-2} \mathrm{~s}^{-1}\right)$ provided by cool white fluorescent tube lamp (100 W each). The lamps were placed at $50 \mathrm{~cm}$ above the culture rack.

After developing 3-4 leaves, the plantlets were transferred to a mixture of sterilized soil:compost:sand $(2: 1: 1, \mathrm{v} / \mathrm{v} / \mathrm{v})$ for acclimatization. The acclimatized plantlets were watered with half strength MS basal medium every other day. Once established, as indicated by formation of new leaves and roots, individual plantlets were planted into a plastic pot (50 cm in diameter and $40 \mathrm{~cm}$ in height) containing $10 \mathrm{~kg}$ potting medium (a mixture of soil:compost:sand=1:1:1, $\mathrm{v} / \mathrm{v} / \mathrm{v}$ ). The pots were placed in a shaded greenhouse for a week and exposed to full sun afterward. The relative humidity in the greenhouse during the dry period ranged from $50-64 \%$ and during the rainy period ranged from $79-89 \%$.

The plantlets producing mature seeds were assigned as the $\mathrm{R} 0$ lines and the harvested R1 seeds were labeled separately.
The R1 seeds were planted and R1 plants grown from R1 seeds were evaluated under greenhouse conditions. The R1 plants producing mature seeds were selected and the harvested R2 seeds were kept separately. The R2 seeds were planted and R2 plants grown from R2 seeds were evaluated under greenhouse conditions.

In all evaluations, peanut cv. 'Kelinci' grown from seeds was also planted as standard. The standard population was also subjected to similar steps of evaluation as in R0, R1, and $\mathrm{R} 2$ lines, respectively.

In each of the evaluation, above ground biomass, primary root length and total pod yield data from each plant were recorded. Statistical analysis of the means and one-way analysis of variance was conducted. Significant differences among population means were compared by Least Significant Difference (LSD) Test using Statistical Analysis Software (SAS) version 9.0.

In addition to simple statistic evaluation, the data were also grouped into five classes and the distribution frequency of the plants based on the observed quantitative characters were determined and graphed for each population. The possible existence of variation was inferred when there were differences in the distribution of the classes among evaluated plants in each population (i.e. the R0, R1, and R2 of SE derived versus standard seed-derived populations). If for any of the quantitative characters, the distribution frequency of the plants derived from SEs was wider than the standard one, it was regarded as an indicator for the presence of somaclonal variants. The plants having lower value than the least of the standard population were regarded as negative variants, whereas the plants having higher value than the highest of the standard population were regarded as positive variants.

\section{Identification of PEG stress tolerant EC and SE}

The sub-lethal concentration of PEG 6000 identified from previous experiment was added to MS-P16 medium and was used to identify putative PEG stress tolerant variants. As many as 500 clumps of peanut EC, each containing 8 to 10 SEs were cultured (five clumps of EC per vial) on selective medium containing sub-lethal PEG 6000 for a total of 3-month period. The cultures were transferred onto fresh selective medium every month. At the end of the selection period, surviving EC and SEs were proliferated on solid MS-P16 medium without PEG for two months. Subsequently, they were subjected for plantlets regeneration following the described procedures in the section of somaclonal variant regeneration. The $\mathrm{R} 1$ seeds were harvested from surviving $\mathrm{R} 0$ plantlets and $\mathrm{R} 2$ seeds were harvested from R1 plants. The R1:2 peanut seeds were used in the following experiment for drought stress evaluation. 


\section{Identification of drought tolerant variants}

The R2 seeds, derived from previously identified PEG stress tolerant SEs was planted in greenhouse (R2 plants). The original peanut cv. 'Kelinci' planted from seeds (i.e. standard plants) was also grown under similar conditions. Evaluated peanut plants were grown individually in a plastic pot $(50 \mathrm{~cm}$ in diameter and $40 \mathrm{~cm}$ in height), each containing $10 \mathrm{~kg}$ of potting medium (a mixture of soil:compost:sand $=1: 1: 1, \mathrm{v} / \mathrm{v}$ ). For each treatment, eighteen peanut lines of the respective populations were evaluated.

The 18 lines of the R2 generation were grown under drought stress conditions during the period of vegetative up to generative stages (12-80 days after planting). The other 18 lines of the R2 generation were grown under optimum conditions. Similarly, 18 plants of the standard population were also grown under drought stress and the other 18 plants under optimum conditions. The drought conditions were administered by watering the treated plants only after $75 \%$ of their leaves wilted. In the experiment, if leaves of the evaluated peanut plants wilted more than $75 \%$, they would not recover and eventually died. The water were added up to field capacity and the plants were maintained until $75 \%$ of their leaves wilted again, and so on. The water was withheld up to four days at the vegetative growth stage (8 weeks after planting) and up to two days at the generative stage to get $75 \%$ leaf wilting. The plants grown under optimal conditions were watered every other day up to field capacity. Both peanut populations were grown to maturity and harvested at 115 days after planting.

Observations were conducted for the following characters: plant height, fresh and dry weight of above ground biomass and roots, total pod numbers, and filled (matured) pod numbers at harvest. Dry weight of above ground biomass and roots were weighted after oven drying at $60^{\circ} \mathrm{C}$ for 3 days. The collected data were statistically analyzed using two-way analysis of variance (ANOVA) and differences among treatments and populations were determined using least significant difference (LSD) test. The statistical analysis was conducted using Statistical Analysis System (SAS), version 9.0.

Drought sensitivity index (DSI), calculated using the following equation (Fischer and Maurer, 1978), was used to identify responses of the evaluated plants against drought stress.

DSI $=\frac{\left(1-\frac{Y p}{Y}\right)}{\left(1-\frac{X p}{X}\right)}$

In that equation, Yp was the average of filled pod yield under drought stress, while $\mathrm{Y}$ was the average filled pod yield under optimum conditions. The $\mathrm{Xp}$ was the average yield of all plants under drought stress, while $\mathrm{X}$ was the average yield of all plants under optimum conditions. The evaluated lines were identified as tolerant if their DSI $<0.5$, medium tolerant if $0.5<\mathrm{DSI} \leq 1.0$, and sensitive against drought stress if DSI $>1.0$.

\section{RESULTS AND DISCUSSIONS}

\section{PEG inhibitory concentration}

Evaluating the effects of PEG supplementation in the media against proliferating peanut embryogenic calli (EC) is necessary before using PEG to identify drought tolerant mutants. Too much PEG 6000 in the medium might kill all of the cultured cells whereas too little PEG resulted in regenerating too many plantlets (Matheka et al., 2008). Effective concentration of PEG in the medium should promote the survival of drought tolerant cells or tissues but inhibit the survival of the others (Widoretno et al., 2003).

Peanut EC of all three cultivars proliferated and formed SEs on liquid MS-P16 medium (Fig. 1a). A close-up representative of proliferated EC and SEs of peanut $\mathrm{cv}$. 'Kelinci' after three months in culture is presented in Fig. $1 \mathrm{~b}$. Supplementing PEG 6000 into MS-P16 medium inhibited peanut EC and SE proliferation. Tissue browning and reduced SEs formation from peanut EC were observed even in the medium with 5\% PEG 6000 (Fig. 1c). Higher PEG concentrations resulted in more severe tissue browning and inhibitory effects on SE formation (Fig. 1d-i).

Different peanut cultivars responded differently to PEG stress. Peanut cv. 'Singa' exhibited the best responses against added PEG in the medium. Peanut cv. 'Kelinci' and peanut cv. 'Badak' exhibited more severe inhibitory effect of PEG in the media (Fig. 1d-e and $1 \mathrm{~g}$-h) than peanut $\mathrm{cv}$. 'Singa' (Fig. 1f and 1i). Significant inhibition on EC and SEs proliferation was observed on selective medium containing 10\% PEG 6000 (Table 1). The EC of peanut cv. 'Kelinci' and 'Singa' survived and proliferated SEs equally well on selective medium supplemented with $10 \%$ or $15 \%$ PEG 6000 (Table 1). At $15 \%$ of PEG 6000 , none of the EC of peanut cv. 'Badak' survived after three months in culture, nor did they proliferated any SE (Table 1). When subjected to selective medium containing $20 \%$ PEG, only a small fraction of EC of peanut cv. 'Kelinci' and 'Singa' survived after three months. They also proliferated fewer SEs per explant (Table 1). None of the EC of peanut cv. 'Badak' survived nor proliferated SEs on medium supplemented with 20\% PEG (Table 1).

All peanut cultivars showed at least $90 \%$ less number of SEs/explant on selective medium supplemented with 15\% 

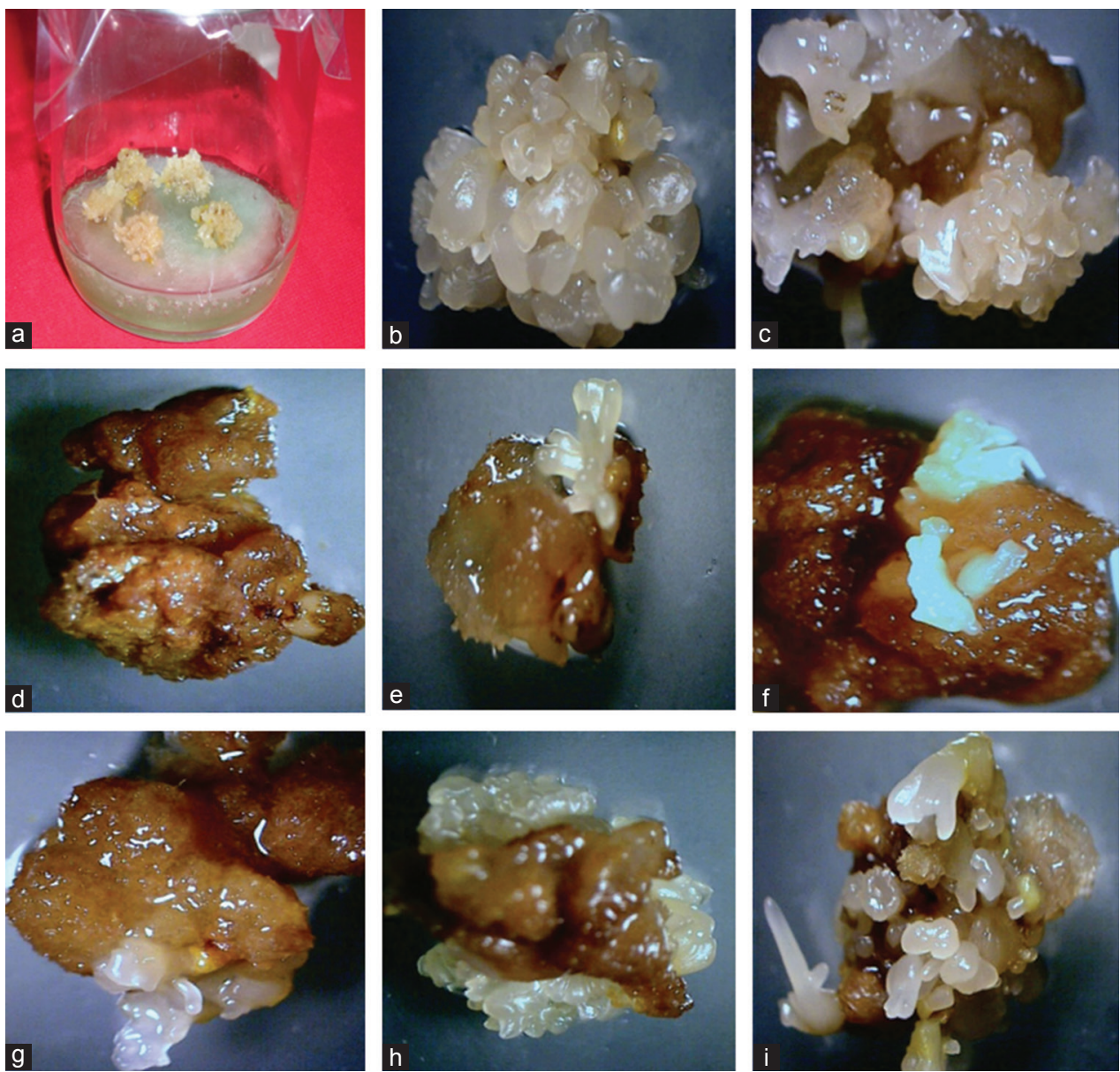

Fig 1. Representative responses of peanut embryogenic calli (EC) and somatic embryos (SEs) cultured on MS-P16 medium with or without adding PEG 6000. (a) Proliferation of peanut embryogenic calli (EC) and somatic embryos (SEs) on a raft floated on the liquid MS-P16 medium. (b) Representative of EC and SEs grown on media without PEG (PEG 0\%), and (c) on 5\% PEG. Responses of EC and SEs on selective medium supplemented with 10\% PEG: (d) Peanut cv. 'Badak,' (e) Peanut cv. 'Kelinci,' and (f) Peanut cv. 'Singa.' Responses of EC and SEs on selective medium supplemented with 15\% PEG: (g) Peanut cv. 'Badak,' (h) Peanut cv. 'Kelinci,' and (i) Peanut cv. 'Singa,' respectively.

of PEG 6000 than those on MS-P16 medium without PEG (PEG 0\%). PEG 6000 at 15\% was selected as sub-lethal PEG level. Culturing EC and SEs for three months on liquid MS-P16 medium supplemented with $15 \%$ of PEG might be used to identify PEG stress tolerance EC and SEs.

Supplementing PEG 6000 into MS-P16 medium resulted in inhibition of EC and SE proliferation of three peanut cultivars. The higher PEG concentration added in the medium, the lower the development and proliferation of SE. Matric forces of ethylene oxide sub-units of the PEG polymer results in low osmotic pressure in the medium. The ethylene oxide sub-units retain water through the formation hydrogen bonds (Steuter, 1981; Kawasaki et al., 1983; Abdel-Raheem et al., 2007; Sayar et al., 2010). Therefore, in the selective medium supplemented with PEG 6000, water molecule in the medium become less available and they cannot be absorbed directly by the growing explants. Lower osmotic pressure might inhibit EC and SEs proliferation and development on the selective medium containing 15\% PEG.
PEG-induced lower water potential might result in either cytoplasmic or vacuolar volume decline because of water removal from the cells (Chartzoulakis et al., 2002). Those conditions might also have happened in peanut EC and SE cultured on MS-P16 medium containing 15\% PEG, leading to lower survival and reduced SE proliferation. Browning and dying of EC and SEs grown on PEG supplemented medium might also be due to water loss induced by osmotic stress or a high phenol production (Sakthivelu et al., 2008).

Browning rate, survival and regeneration of calli have been used as indicators to select for dehydration stress tolerant variants (Wani et al., 2010; Aazami et al., 2010). Browning rate has been suggested as a good indicator for plant calli sensitivity to PEG 6000 stress (Mahmood et al., 2012b). PEG stress tolerant callus tended to show less browning and higher survival rates under high level of PEG 6000 (Mahmood et al., 2012b). Our results were in line with results of those studies on PEG stress tolerance in plants. By adding PEG 6000 in the selective medium, callus proliferation reduced as well as in-vitro regeneration 
capacity of potato (Gopal and Iwama, 2007), soybean (Sakthivelu et al., 2008), tomato (Aazami et al., 2010), and wheat (Sayar et al., 2010). In previous experiments (Rahayu et al., 2005), inhibition of in-vitro shoot growth of peanut by PEG 6000 also correlated with the level of drought stress tolerant in peanut. Similar correlations have also been observed in sugarcane (Saccharum bybrids) (Wagih et al., 2004).

\section{Regeneration of somaclonal variants}

Most of the regenerated plantlets of peanut cv. 'Kelinci' (150 plantlets) did not survive at acclimatization stage and only 62 plantlets survived as R0 plants in the greenhouse. Out of those, only $24 \mathrm{R} 0$ plants were normally developed and reached reproductive stage. Nine $\mathrm{R} 0$ plants produced mature pods and yielded R0-1 seeds. The number of yielded total pods/plant among the R0 plants varied between 4-16 while that of filled pods/plant were 4-13, respectively. Representative photos of SE germination up to R0 plant regeneration are presented in Fig. 2a-i.

Three R1 seeds randomly sampled from each of the best nine R0 plants were planted to obtain a total of 27 $\mathrm{R} 1$ lines. All of the evaluated R1 lines produced mature pods (3-15 pods per plant). Some of the regenerated lines are producing normal number of pods/plants, some producing less than normal (probably a negative mutants for pod yield), and a few producing higher than normal pod numbers/plant. The R1s producing low number of pods/plant were usually derived from R0 plants that are either producing more above ground biomass but less flowers or having abnormal flowers (partial male sterile). Since the R1 plants yielding low number of pods were also derived from those $\mathrm{R} 0$ with low pod yield, it is our opinion that low numbers of pods/plant yields are not because of degeneration or decline in the quality of the somaclones. Some of the morphological abnormalities were inherited into the R1 and R2 generation, such as: more biomass production and partial male sterility as it has been reported by Rahayu and Sudarsono (2009a), indicating that the characters are genetically controlled.

On the other hand, a number of R0 plants yielded normal or higher number of pods/plant. The R1 and R2 lines derived from these R0 plants yielding high number of pods/plant also produce high number of pods, indicating the possible sexual inheritance of the character. This finding was in line with previous findings that in vitro
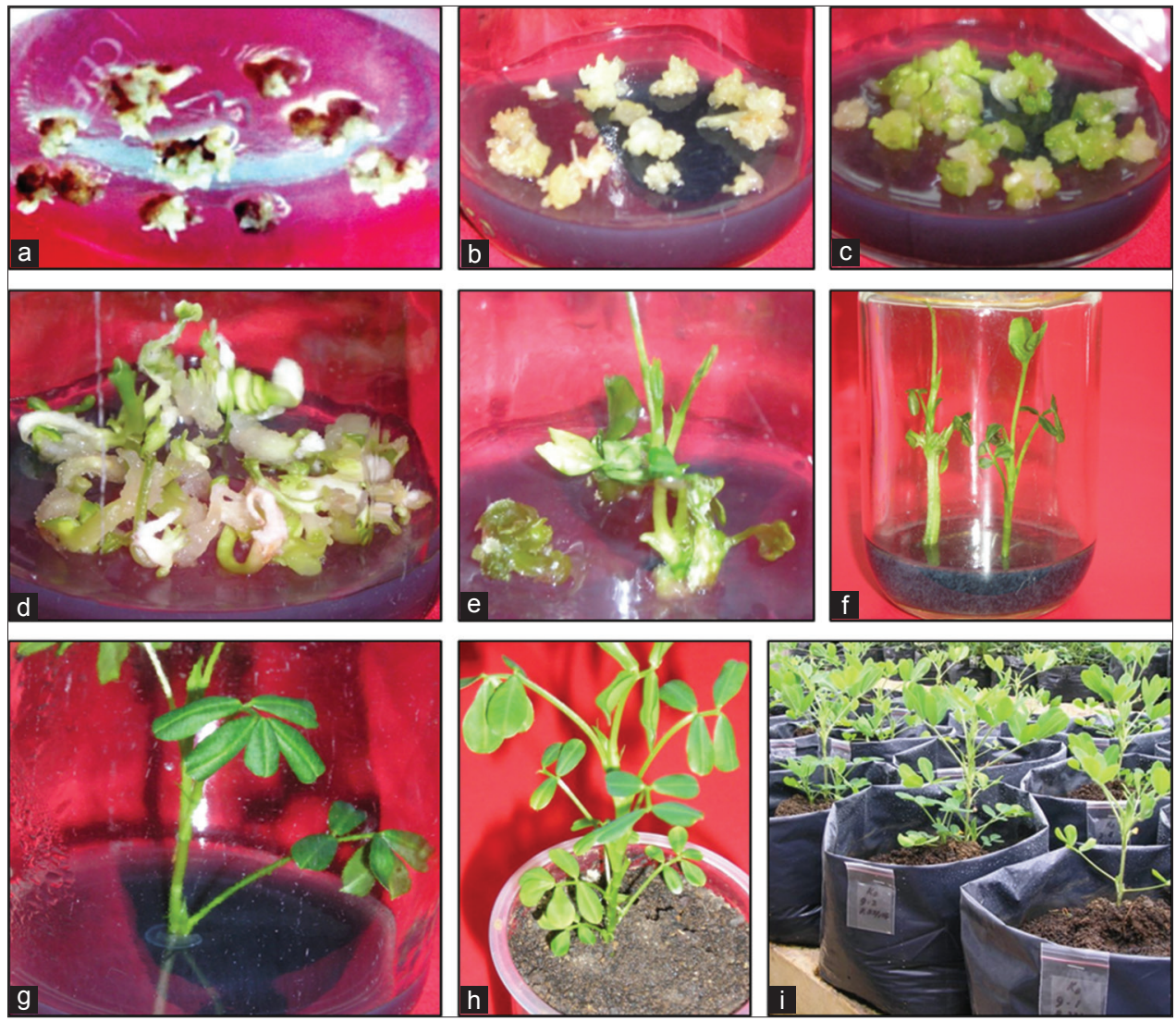

Fig 2. PEG stress tolerance peanut somatic embryos (SE), SE germination, and Plantlet regeneration. (a) PEG stress tolerance peanut SEs one month after recovery in MS-P16 medium. (b) and (c) SE maturation on MS-AC medium. (d) Germination of mature SEs on MS-AC medium. (e) Regenerated shoot from germinated SE on MS-AC medium containing $22 \mu \mathrm{M}$ BAP. (f) Root induction from regenerated shoots on MS-AC containing $10 \mathrm{mg} / \mathrm{INAA}$. (g) Rooted plantlet on MS-AC medium. (h) Surviving plantlet after acclimatization. (i) Surviving R0-plants in the glasshouse. 
derived variation could yield plant variants with improved yield (Jain 2001). Three R2 seeds randomly sampled from each of the best R1 were planted to obtain a total of 27 R2 lines.

Table 2 presents mean of above ground biomass (AGB) of the evaluated R0, R1 and R2 plants. In general, the R0 plants yielded more AGB than those of standard peanut cv. 'Kelinci.' On the other hand, the R1 and R2 plants yielded less AGB than those of standard (Table 2). Primary root length (PRL) of R0, R1 and R2 plants were shorter and the total pod number (TPN) was fewer than those of standard peanut cv. 'Kelinci' (Table 3). A photograph comparing roots of the $\mathrm{R} 0$ derived from $\mathrm{SE}$ and the standard peanut cv. Kelinci grown fom seed was presented in Fig. 3. Although frequency distribution of R0, R1, and R2 plants based on its PRL was similar to that of control line there were two R2 plants showing longer PRL than those of control. These two R2 plants had PRL of $>34.2 \mathrm{~cm}$. There were $11 \mathrm{R} 2$ plants yielded less TPN than those of

Table 1: The average number of surviving explants per vial, the number of SE per explant, and their percentages of relative reduction to $0 \%$ PEG for peanut cv. 'Badak,' 'Kelinci,' and 'Singa' grown for three months on selective medium containing $5 \%, 10 \%, 15 \%$ or $20 \%$ of PEG

\begin{tabular}{|c|c|c|c|c|c|c|}
\hline \multirow[t]{2}{*}{$\begin{array}{l}\text { PEG } \\
(\%)\end{array}$} & \multicolumn{3}{|c|}{$\begin{array}{c}\text { Number of surviving } \\
\text { explant/vial }\end{array}$} & \multicolumn{3}{|c|}{$\begin{array}{c}\text { Relative reduction (\%) } \\
\text { to PEG } 0 \% \text { a }\end{array}$} \\
\hline & 'Badak' & 'Kelinci' & 'Singa' & 'Badak' & ‘Kelinci’ & 'Singa' \\
\hline 0 & 5.0 & 5.0 & 5.0 & 0 & 0 & 0 \\
\hline 5 & 4.4 & 5.0 & 5.0 & 12 & 0 & 0 \\
\hline 10 & 3.0 & 4.2 & 4.4 & 40 & 16 & 12 \\
\hline 15 & 0 & 2.2 & 2.2 & 100 & 56 & 56 \\
\hline \multirow[t]{2}{*}{20} & 0 & 0.6 & 1.0 & 100 & 88 & 80 \\
\hline & \multicolumn{3}{|c|}{$\begin{array}{l}\text { Number of SE } \\
\text { per explant }\end{array}$} & \multicolumn{3}{|c|}{$\begin{array}{c}\text { Relative reduction (\%) } \\
\text { to PEG } 0 \%{ }^{\mathrm{a}}\end{array}$} \\
\hline 0 & 32.1 & 36.0 & 34.4 & 0 & 0 & 0 \\
\hline 5 & 25.6 & 25.2 & 23.5 & 20 & 30 & 32 \\
\hline 10 & 2.6 & 11.2 & 12.2 & 92 & 69 & 65 \\
\hline 15 & 0 & 3.4 & 3.8 & 100 & 91 & 90 \\
\hline 20 & 0 & 0 & 1.2 & 100 & 100 & 96 \\
\hline
\end{tabular}

aPercentages of relative reduction (RR) to PEG $0 \%$ was calculated using the following equation $\mathrm{RR}=[(\mathrm{np} 0-\mathrm{npN}) /(\mathrm{np} 0)]^{\star} 100 \%$; $\mathrm{np} 0=$ The observed value on medium without PEG (PEG $0 \%$ ); npN=The observed value on medium containing either PEG $5 \%, 10 \%, 15 \%$, or $20 \%$ standard plants. These 11 plants had TPN of $<4.2$ pods per plant (Table 4).

Addition of picloram (trichloropicolinic amino acid) into MS-P16 medium was effective to induce embryogenic callus (Edy, 1998; Sulichantini, 1998). It was reported previously synthetic auxin induced cell division and enlargement (Companoni and Nick, 2005) which led to formation of somatic embyos. Picloram was also used for callus and SE induction of Phyla nodiflora (Ahmed et al., 2011) and peanut leaf explants (Edy, 1998; Sulichantini, 1998) and coconut endosperm (Sukamto, 2011).

The peanut lines regenerated from SEs with characters deviated from those of the standard lines might have been variants for the characters. Culture period of six months on MS medium containing picloram (MS-P16) was long enough to allow repeated division of the callus. Auxin concentration in callus induction and number of subcultures are major factors affecting somaclonal

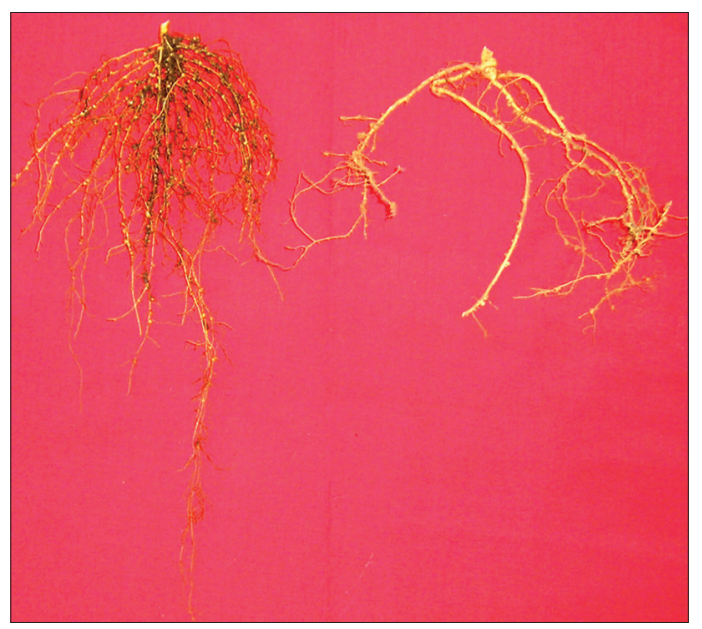

Fig 3. Representative example of roots of the standard peanut cv. Kelinci from seed (left) and the R0 plants developed from somatic embryo (SE) in this experiment (right). The SE maturation and germination were conducted on MS medium containing activated charcoal (MS-AC) followed by shoot regenation om MS medium containing BAP. Subsequetly, the regenerated shoot were excised and transferred onto MS medium containing $10 \mathrm{mg} / \mathrm{I} \mathrm{NAA} \mathrm{for} \mathrm{root}$ induction. Rooting was conducted by culturing the shoot onto MS-AC prior to transplanting into soil medium.

Table 2: The means of above ground biomass (AGB) weight and distribution frequency of R0, R1, and R2 plants and the standard peanut cv. 'Kelinci' based on their AGB weight. The R0, the R1, and the R2 plants were regenerated from peanut somatic embryos (SE) without in-vitro selection

\begin{tabular}{|c|c|c|c|c|c|c|c|}
\hline \multirow[t]{2}{*}{ Population } & \multirow{2}{*}{$\begin{array}{c}\text { Total } \\
\text { number of } \\
\text { plants }\end{array}$} & \multirow{2}{*}{$\begin{array}{l}\text { Mean of AGB } \\
\text { weight }(g)\end{array}$} & \multicolumn{5}{|c|}{ Number of plants with AGB weight $(g)$} \\
\hline & & & $<96.5$ & $96.5-185.9$ & $185.9-275.2$ & $275.2-364.6$ & $>364.6$ \\
\hline Standard & 27 & 109.7 & 14 & 13 & 0 & 0 & 0 \\
\hline Ro & 24 & 186.2 & 12 & 5 & $3^{*}$ & $2^{*}$ & $2^{*}$ \\
\hline $\mathrm{R} 1$ & 27 & 60.8 & 27 & 0 & 0 & 0 & 0 \\
\hline $\mathrm{R} 2$ & 27 & 36.4 & 27 & 0 & 0 & 0 & 0 \\
\hline
\end{tabular}

*Plant having biomass higher than standard plant populations, most probably variants for this character 
Table 3: Means of the primary root length (PRL) and distribution frequency of R0, R1, and R2 plants and the standard peanut cv. 'Kelinci' based on their PRL. The R0, the R1, and the R2 plants were regenerated from peanut somatic embryos (SE) without in-vitro selection

\begin{tabular}{|c|c|c|c|c|c|c|c|}
\hline \multirow[t]{2}{*}{ Population } & \multirow{2}{*}{$\begin{array}{c}\text { Total } \\
\text { number of } \\
\text { plants }\end{array}$} & \multirow{2}{*}{$\begin{array}{l}\text { Mean of } \\
\text { PRL }(\mathrm{cm})\end{array}$} & \multicolumn{5}{|c|}{ Number of plants with PRL (cm) } \\
\hline & & & $<13.8$ & $13.8-20.6$ & 20.6-27.4 & 27.4-34.2 & $>34.2$ \\
\hline Standard & 27 & 22.7 & 3 & 8 & 12 & 4 & 0 \\
\hline Ro & 24 & 16.8 & 9 & 10 & 4 & 1 & 0 \\
\hline $\mathrm{R} 1$ & 27 & 18.5 & 5 & 18 & 3 & 1 & 0 \\
\hline $\mathrm{R} 2$ & 27 & 17.7 & 9 & 11 & 3 & 2 & $2^{*}$ \\
\hline
\end{tabular}

*Plant having primary root length higher than standard plant populations, most probably variants for this character

Table 4: Means of total pod number (TPN) and distribution frequency of R0, R1, and R2 plants and the standard peanut cv. 'Kelinci' based on their TPN. The R0, the R1, and the R2 plants were regenerated from peanut somatic embryos (SE) without in-vitro selection

\begin{tabular}{|c|c|c|c|c|c|c|c|}
\hline \multirow[t]{2}{*}{ Population } & \multirow{2}{*}{$\begin{array}{c}\text { Total } \\
\text { number } \\
\text { of plants }\end{array}$} & \multirow{2}{*}{$\begin{array}{c}\text { Mean } \\
\text { of } \\
\text { TPN }\end{array}$} & \multicolumn{5}{|c|}{ Number of plants with TPN } \\
\hline & & & $<4.2$ & $4.2-8.4$ & 8.4-12.6 & $12.6-16.8$ & $>16.8$ \\
\hline Standard & 27 & 14.2 & 0 & 2 & 11 & 12 & 2 \\
\hline Ro & $24^{*}$ & 6.8 & 0 & 5 & 3 & 1 & 0 \\
\hline $\mathrm{R} 1$ & 27 & 9.5 & 0 & 15 & 9 & 3 & 0 \\
\hline $\mathrm{R} 2$ & 27 & 5.9 & $11^{* *}$ & 10 & 5 & 1 & 0 \\
\hline
\end{tabular}

${ }^{*}$ Out of 24 R0 plants, only 9 R0 plants produced mature pods. **Plant having total pod number lower than standard plant populations, most probably variants for this character

variation in an in vitro culture (Gaafar and Saker, 2006). Fast and repeated cell divisions could induce somaclonal variation through changes in chromosome numbers and rearrangements, DNA methylations, and point mutations (Kaeppler et al., 1998; Kumar and Mathur, 2004). Frequency of somaclonal variation correlated with the length of culturing period (Bouman and de Klerk, 1997; Rodrigues, 2008; Valledor et al., 2007) and this correlation was confirmed in Picea mariana and P. glauca (Tremblay et al., 1999), Asparagus officinalis (Pontaroli and Camadro, 2005), Dieffenbachia (Shen et al., 2007), and wheat (Mahmood et al., 2012a).

\section{Identification of PEG stress tolerant EC and SE}

Most of the EC and SEs of peanut cv. 'Kelinci,' cultured on selective medium supplemented with 15\% PEG 6000 , turned brown and died. Out of 500 clumps of EC containing about of 4000-5000 SEs cultured on the selective medium, only 415 grew normally and looked fresh white. These normally growing SEs on selective MS-P16 medium containing 15\% PEG were PEG stress tolerant; therefore, these activities identified the presence of PEG stress tolerant EC and SEs. Since addition of PEG in selective media causes dehydration stress, PEG stress tolerant EC and SEs could also be drought stress tolerant SE variants. Hence, peanut plants regenerated from PEG stress tolerance $\mathrm{EC}$ and SEs could also be drought stress tolerance.

Plantlet regeneration from the PEG stress tolerant SEs resulted in 140 plantlets with normal shoots and root morphologies. After acclimatization, $54 \mathrm{R} 0$ plants survived and 18 plants reached reproductive stages and yielded mature pods (Table 5). Representative photos of the R0 plant regenerated from SE and standard plant from seeds; the R1 plants and the R2 plants are presented in Fig. 4a-c. Representative photos of the R2 plant under optimum conditions; the above ground biomass and harvested pods of an R2 plant under optimum conditions are presented in Fig. 4d-f while the R2 plant under drought stress; the above ground biomass and the harvested pods of a tolerant R2 plant under drought stress conditions are presented in Fig. $4 \mathrm{~g}-\mathrm{i}$.

Out of $18 \mathrm{R} 0$ plants, nine plants yielding the highest pods were selected. Two R0-1 seeds from each of the selected R0 plant were planted to generate R1 plants. Out of 18 R1 plants, nine plants yielding the highest number pods were further selected. Four R1-2 seeds from each of the selected plants were taken and planted to generate R2 plants. Therefore, there were $36 \mathrm{R} 2$ plants available for further evaluation (Table 5). Response of these R2 plants against drought stress under greenhouse conditions were evaluated in the next experiment.

\section{Identification of drought tolerant variants}

The R2 plant mean values for a number of recorded parameters under optimum conditions were lower than those of standard ones (Table 6). Based on their filed pod yield under optimum conditions, the distribution frequency of R2 plants was similar to those of standard peanut $\mathrm{cv}$. 'Kelinci' (Fig. 5). However, one R2 plant yielded more numbers of filled pods under optimum conditions than those of the standard plants (Fig. 4) and this was probably a possitive plant variant for yield character.

Under the described drought stress conditions, both standard and R2 plants exhibited lower values for all recorded parameters compared to those under optimum conditions (Table 6). However, the percentages of reduction because of drought stress for the R2 plants were smaller than those of standard plants (Table 6). Under drought stress conditions, the distribution frequency of R2 plants was also wider than those of standard plants (Fig. 5). Three 



Fig 4. Peanut plants developed from PEG stress tolerance somatic embryos (SE). Representative of (a) the R0 plant (left) regenerated from SE and control plants (right) from seeds at 8 weeks after planting (wap); (b) the R1 plants at 8 wap and (c) the R2 plants at 12 wap. (d) The R2 plant under optimum conditions at 4 wap. (e) Above ground biomass and (f) harvested pods of an R2 plant under optimum conditions. (g) The R2 plant under drought stress conditions at 4 wap. The photograph was taken 3 days after the last watering. (h) Above ground biomass and (i) harvested pods of a tolerant R2 plant under drought stress conditions.

Table 5: Effectiveness of regenerating peanut plants originated from PEG stress tolerant embryogenic calli (EC) and somatic embryos (SEs) identified on MS-P16 medium supplemented with sub-lethal concentration of PEG 6000 (15\%)

\begin{tabular}{lc}
\hline Evaluated variables & Number \\
\hline Number of initial EC clumps (SEs) & 500 (4000-5000) \\
Number of identified PEG stress tolerant SEs & 415 \\
$\begin{array}{l}\text { Number of regenerated plantlets from PEG } \\
\text { stress tolerant SE }\end{array}$ & 140 \\
Number of regenerated R0 plants & 54 \\
Number of R0 plants yielding matured pods & 18 \\
$\begin{array}{l}\text { Number of selected R1 plants with highest } \\
\text { pod numbers }\end{array}$ & 9 \\
Number of selected R2 plants with highest & 9 \\
pod numbers & \\
\hline
\end{tabular}

Note: *Each clump of EC contained 8-10 SEs

R2 plants showed higher filled pod yield under drought conditions than those of the standard (Fig. 5).

Such results indicated that the employed drought conditions did not significantly affect peanut R2 plants as compared to that of the control ones. The results also indicated that the R2 plants, regenerated from PEG stress tolerant SEs, coped better to drought stress under greenhouse conditions than Emir. J. Food Agric • Vol $27 \bullet$ Issue 6 • 2015 those of standard plants. Moreover, three R2 plants exhibited better filled pod yield under drought stress conditions in the greenhouse than those of standard (Fig. 5).

The DSI calculated based on filled pod yield in this experiment indicated that the standard plant (peanut cv. 'Kelinci') was identified as sensitive against drought stress (DSI>1, Fig. 5). On the other hand, the R2 plants regenerated from PEG 6000 stress tolerant SEs were identified either as sensitive against drought stress $\mathrm{SI}>1 ; 8$ lines), medium tolerant $(0.5<\mathrm{DSI}<1 ; 2$ lines), or tolerance (DSI $<0.5 ; 8$ R2 lines) (Table 7, Fig. 6). One of the identified drought tolerance plant (K15-4.1.1), was also the positive variant for filled pods yield character. Therefore, this K15-4.1.1 variant could potentially be developed as a putative peanut line having both high yield and drought tolerant characters.

PEG 6000 stress tolerant EC and SE variants regenerated drought tolerant R2 plants. Continuously proliferated EC and SE for six month yielded these PEG 6000 stress tolerant EC and SEs from PEG sensitive standard peanut cv. 'Kelinci.' Therefore, those EC and SE variants might 
Table 6: Mean differences and standard deviation of quantitative characters between the original peanut cv. 'Kelinci' (standard) and the variant $R 2$ lines regenerated from PEG stress tolerance peanut somatic embryos (SEs), identified on MS-P16 medium supplemented with $15 \%$ PEG 6000 , grown under optimum and drought stress conditions in the greenhouse

\begin{tabular}{|c|c|c|}
\hline \multirow[t]{2}{*}{ Quantitative characters } & \multicolumn{2}{|c|}{$\begin{array}{l}\text { Mean and standard deviation } \\
\text { of the population }\end{array}$} \\
\hline & Standard & R2 plants \\
\hline \multicolumn{3}{|l|}{ Plant height (cm) } \\
\hline Optimum & $68.5 a A \pm 12.5$ & $35.6 b A \pm 9.7$ \\
\hline Stress & $13.7 \mathrm{bB} \pm 3.2$ & $21.5 \mathrm{aB} \pm 6.0$ \\
\hline Reduction (\%) & 80 & 40 \\
\hline \multicolumn{3}{|l|}{ Above ground biomass (g) } \\
\hline Optimum & $109.7 \mathrm{aA} \pm 3.3$ & $42.2 \mathrm{bA} \pm 17.5$ \\
\hline Stress & $11.1 \mathrm{bB} \pm 1.2$ & $30.7 \mathrm{aB} \pm 16.9$ \\
\hline Reduction (\%) & 90 & 38 \\
\hline \multicolumn{3}{|l|}{ Shoot dry weight (g) } \\
\hline Optimum & $25.4 \mathrm{aA} \pm 6.3$ & $12,9 b A \pm 4.4$ \\
\hline Stress & $5.6 b B \pm 2.3$ & $11,8 \mathrm{a} A \pm 3.4$ \\
\hline Reduction (\%) & 78 & 8 \\
\hline \multicolumn{3}{|l|}{ Root fresh weight (g) } \\
\hline Optimal & $4.2 \mathrm{aA} \pm 1.1$ & $1.1 b A \pm 0.7$ \\
\hline Stress & $0.5 \mathrm{aB} \pm 0.2$ & $0.6 \mathrm{aB} \pm 0.3$ \\
\hline Reduction (\%) & 87 & 46 \\
\hline \multicolumn{3}{|l|}{ Root dry weight (g) } \\
\hline Optimal & $1.0 \mathrm{aA} \pm 0.3$ & $1.1 \mathrm{aA} \pm 0,6$ \\
\hline Stress & $0.3 a \mathrm{aB} \pm 0.1$ & $0.3 \mathrm{aB} \pm 0.1$ \\
\hline Reduction (\%) & 71 & 69 \\
\hline \multicolumn{3}{|l|}{ Total pods number } \\
\hline Optimal & $22.5 \mathrm{a} A \pm 5.6$ & $10.7 \mathrm{bA} \pm 6.6$ \\
\hline Stress & $5.3 b B \pm 1.5$ & $12.0 \mathrm{aA} \pm 6.0$ \\
\hline Reduction (\%) & 76 & 13 \\
\hline \multicolumn{3}{|l|}{ Filled pods number } \\
\hline Optimal & $14.2 \mathrm{aA} \pm 3.5$ & $8.1 b A \pm 5.2$ \\
\hline Stress & $4.0 \mathrm{bB} \pm 1.0$ & $8.2 \mathrm{aA} \pm 3.9$ \\
\hline Reduction (\%) & 72 & 0 \\
\hline
\end{tabular}

Note: In each character, mean values in a column followed by the same capital letter and in a row followed by the same lower letter, respectively, were not significantly different based on DMRT at $\alpha=5 \%$

acquire PEG stress tolerant mechanisms during EC or SEs proliferation. Such acquired mechanisms might also be the ones responsible for drought stress tolerant characters under greenhouse conditions.

There are two known mechanisms for plants to evade negative effects of drought stress, such as: the drought stress avoidance and the tolerant mechanisms. The stress avoidance is the ability of plant to maintain high tissue water potential under drought stress. Plants achieve such status by enhancing water uptake through deep rooting systems or reducing transpiration loss through smaller or succulent leaves (Mundree et al., 2002; Farooq et al., 2009).

In previous finding using the same population of peanut variants, the new mechanisms of drought tolerant might have been identified. Previous investigation also indicated there was a significant positive correlation between stomatal
Table 7: Responses to drought stress of 18 R2 plants regenerated from PEG stress tolerant peanut embryogenic calli (EC) and somatic embryos (SEs), identified on MS-P16 medium supplemented with $15 \%$ PEG 6000 . The evaluated populations were grown under optimum and drought stress conditions in the greenhouse

\begin{tabular}{llccll}
\hline No & Line code & \multicolumn{2}{c}{$\begin{array}{c}\text { Number of filled } \\
\text { pods/plant }\end{array}$} & DSI & Responses \\
\cline { 3 - 4 } & & Drought stress & Optimal & & \\
\hline 1 & K15-1.1-1 & 7.04 & 7.13 & 0.86 & MT \\
2 & K15-1.1-2 & 7.74 & 7.94 & 1.72 & S \\
3 & K15-2.2-1 & 8.14 & 8.35 & 1.72 & S \\
4 & K15-2.2-2 & 7.96 & 8.06 & 0.85 & MT \\
5 & K15-4.1-1 & 8.45 & 8.49 & 0.32 & T \\
6 & K15-4.1-2 & 7.85 & 8.08 & 1.94 & S \\
7 & K15-5.1-1 & 6.91 & 6.95 & 0.39 & T \\
8 & K15-5.1-2 & 7.74 & 7.91 & 1.47 & S \\
9 & K15-5.2-1 & 8.39 & 8.42 & 0.24 & T \\
10 & K15-5.2-2 & 8.23 & 8.28 & 0.41 & T \\
11 & K15-8.2-1 & 7.87 & 8.04 & 1.44 & S \\
12 & K15-8.2-2 & 7.56 & 7.60 & 0.36 & T \\
13 & K15-10.1-1 & 8.15 & 8.37 & 1.79 & S \\
14 & K15-10.1-2 & 8.23 & 8.28 & 0.41 & T \\
15 & K15-10.2-1 & 8.87 & 8.93 & 0.46 & T \\
16 & K15-10.2-2 & 9.12 & 9.34 & 1.61 & S \\
17 & K15-18.2-1 & 8.15 & 8.32 & 1.39 & S \\
18 & K15-18.2-2 & 8.85 & 8.89 & 0.31 & T \\
\hline
\end{tabular}

Note: Based on their drought sensitivity index (DSI), calculated using filled pod yield per plant, 18 plants of peanut cv. 'Kelinci' (standard) were classified as sensitive to drought stress under this experiment. S: Sensitive, MT: Medium tolerant, and T: Tolerant against drought stress under greenhouse conditions

densities and drought susceptibility characters in peanut (Rahayu and Sudarsono, 2009b). Drought tolerance variants identified in this study, however, show stomatal densities lower than those of drought sensitive ones and exhibit no significant correlation between root/shoot ratio and primary root length with drought susceptibility index (Rahayu and Sudarsono, 2009b).

The ability of plant cells to cope with lower water potential inside the plant cells and tissues indicates drought tolerance responses. In general, tolerance mechanisms should consist of preventing or reducing cell damage, maintaining homeostatic, and maintaining plant growth under drought stress conditions (Mundree et al., 2002). Plant cells achieve such status by accumulating osmolyte compounds, such as: glycine-betaine, proline and other amino acids, LEA protein, organic acids, polyols, and soluble sugars (Serraj and Sinclair 2002; Mundree et al., 2002; Farooq et al., 2009; Naguib et al., 2010). Osmolyte compounds also possess an important role in detoxification and osmotic adjustment processes to maintain turgor pressure and function of the cell (Chaves et al., 2009; Farooq et al., 2009).

Adding PEG 6000 into tissue culture medium induced dehydration stress (Steuter, 1981) to the cultured explants. Surviving EC and SEs under such selective medium 


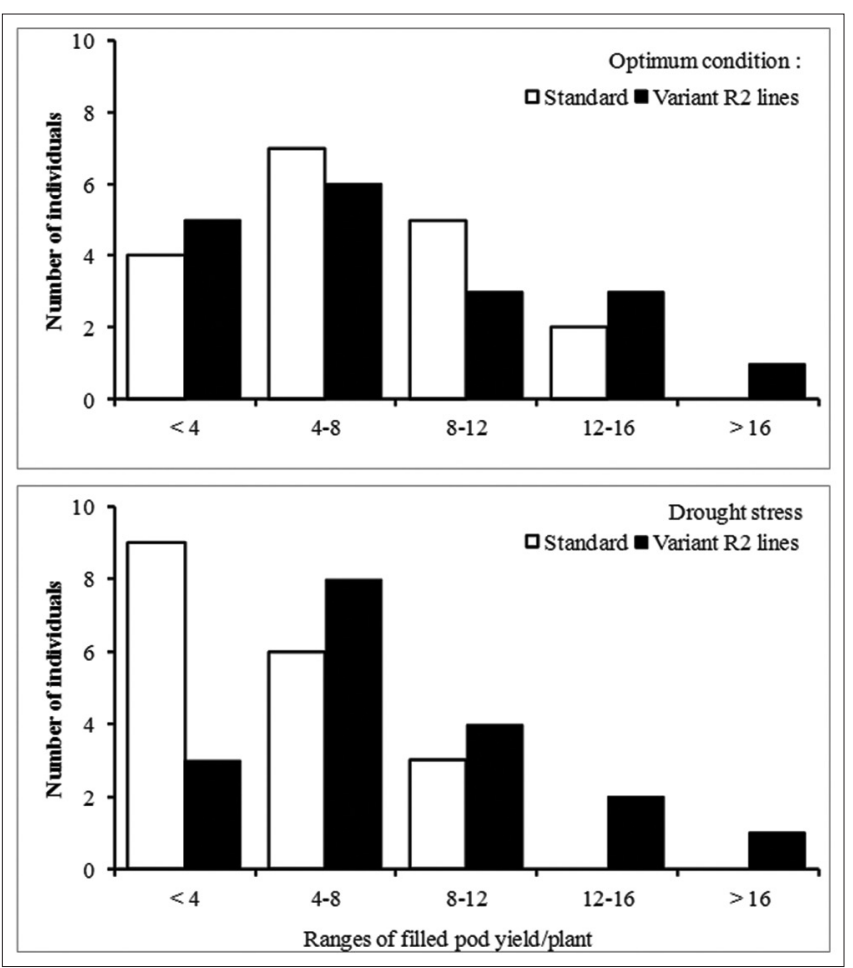

Fig 5. Distribution frequency of R2 plants and those of standard peanut cv. 'Kelinci' based on the filled pod yield under optimum and drought stress conditions in the greenhouse. The R2 were originally generated from PEG stress tolerance EC and SE identified as results of in-vitro selection using MS-P16 medium containing 15\% PEG 6000.

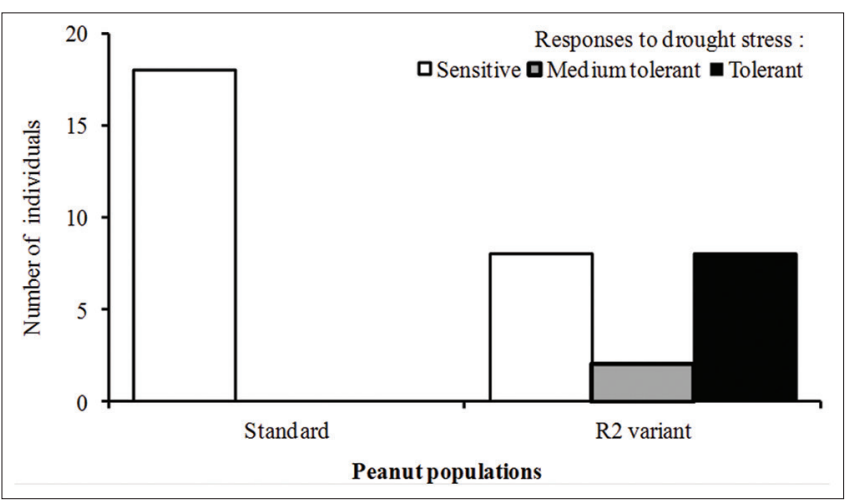

Fig 6. Grouping of responses to drought stress of standard peanut cv. 'Kelinci' (undergo no-in-vitro selection) and the variant R2 plants regenerated from PEG stress tolerance embryogenic calli $(E C)$ and somatic embryos (SEs) identified from in-vitro selection on MS-P16 medium supplemented with $15 \%$ PEG 6000 . Grouping of the responses was based on their drought sensitivity index (DSI), calculated using filled pod yield per plant.

might have indicated they developed from mutant cells and tissues acquiring dehydration stress tolerance mechanisms. Regenerated plants from such EC and SEs might maintain the same mechanisms at plant levels and they might be the same mechanisms causing drought tolerance in identified variant lines. Although PEG induced dehydration stress may be different than drought stress in the field, the tolerance to both conditions might employ similar mechanisms such as maintaining high tissue water potential under the stress. Therefore, selecting for EC and SEs under PEG induced stress may end up with drought tolerant variants (Bajji et al., 2004).

\section{CONCLUSION}

This study demonstrated that regeneration of somaclonal variation is a potential technique to obtain variants in peanut. PEG 6000 supplemented medium could be used to effectively select and regenerate drought tolerant plants. The protocols of in-vitro screening and identification of drought stress tolerant plants developed in this study could be used for future studies. The sub-lethal concentration of PEG 6000 supplemented into MS-P16 for in-vitro selection was 15\%. This concentration effectively inhibited $(\geq 90 \%)$ growth and proliferation of EC and SEs. In-vitro selection of peanut EC and SE variants using 15\% PEG 6000 supplemented MSP16 liquid medium has effectively identified more drought stress tolerant plants than the control ones.

\section{ACKNOWLEDGMENT}

Part of this research was supported by Proyek Peningkatan Penelitian Pendidikan Tinggi, Directorate General of Higher Education, Ministry of National Education - Graduate Team Research Grant (HPTP) - Batch I: Genetic Engineering and In-vitro Selection for the Development of Peanut Germplasm with Novel Characters-Drought Tolerance and Sclerotium Stem Rot Resistance. Contract No. 340/P4T/DPPM/IV. E.S.R. was also supported by TMPD Scholarship for PhD program from the Department of National Education, Republic of Indonesia.

\section{Author contributions}

E. S. R. and S. S. made a major contribution to the paper. This research was part of the E. S. R.'s Ph.D dissertation research. She conducted most of the experiments, analyzed the results, and preparing the draft manuscript. The activities was part of the research project coordinated by S. S. and he was resonsible for planning and designing the whole experiments. S. S. also made a major contribution in data analysis and presentation, manuscript preparation and editing, and he is the major (chairman) of the supervisory committees of E. S. R.'s PhD. program.

\section{REFERENCES}

Aazami, M. A., M. Torabi and E. Jalili. 2010. In-vitro response of promising tomato genotypes for tolerance to osmotic stress. Afr. J. Biotechnol. 9: 4014-4017.

Abdel-Raheem, A. T., A. R. Ragab, Z. A. Kasem, F. D. Omar and A. M. Samera. 2007. In-vitro selection for tomato plants for 
drought tolerance via calli culture under polyethylene glycol (PEG) and mannitol treatments. Proc. Afr. Crop Sci. Conf. 8: 2027-2032.

Ahmed, A. B. A., A. S. Rao, M. V. Rao, and R. M. Taha. 2011. Effect of picloram, additives and plant growth regulators on somatic embryogenesis of Phyla nodiflora (L.) Greene. Braz. Arch. Biol. Technol. 54: 7-11.

Ahmed, M., M. Asif, M. Sajad, J. Z. K. Khattak, W. Ijaz, W. A. Fayyazul-Hassan and J. A. Chun. 2013. Could agricultural system be adapted to climate change? A review. Aust. J. Crop Sci. 7: 16421653.

Bajji, M., P. Bertin, S. Lutts and J. M. Kinet. 2004. Evaluation of drought resistance-related traits in durum wheat somaclonal lines selected in-vitro. Aust. J. Exp. Agric. 44: 27-35.

Barthakur, S., V. Babu and K. C. Bansa. 2001. Over expression of osmotin induces proline accumulation and confers tolerance to osmotic stress in transgenic tobacco. J. Plant Biochem. Biol. 10: 31-37.

Bidabadi, S. S., S. Meon, Z. Wahab, S. Subramaniam and M. Mahmood. 2012. In-vitro selection and characterization of water stress tolerant lines among ethyl methane sulphonate (EMS) induced variants of banana (Musa spp., with AAA genome). Aust. J. Crop Sci. 6: 567-575.

Bouman, H. and G. J. De Klerk. 1997. Somaclonal variation. In: Geneve, R. L., S. E. Preece and S. A. Merkle, editors. Biotechnology of Ornamental Plants. CAB Int., Wallingford, UK. pp. 165-189.

Cassells, A. C. and R. F. Curry. 2001. Oxidative stress and physiological, epigenetic and genetic variability in plant tissue culture: implications for micropropagators and genetic engineers. Plant Cell Tiss. Organ. Cult. 64: 145-157.

Ceccarelli, S., S. Grando, M. Maatougui, M. Michael, M. Slash, R. Haghparast, M. Rahmanian, A. Taheri, A. Al-Yassin, A. Benbelkacem, M. Labdi, H. Mimoun and M. Nachit. 2010. Plant breeding and climate changes. J. Agric. Sci. 148: 627-637.

Chartzoulakis, K., A. Patakas, G. Kofidis, A. Bosabalidis and A. Nastou. 2002. Water stress affects leaf anatomy, gas exchange, water relations and growth of two avocado cultivars. Sci. Hortic. 95: 39-50.

Chaves, M. M., J. Flexas and C. Pinheiro. 2009. Photosynthesis under drought and salt stress: Regulation mechanisms from whole plant to cell. Ann. Bot. 103: 551-560.

Companoni, P. and P. Nick. 2005. Auxin-dependent cell division and cell elongation. 1-naphthaleneacetic acid and 2, 4-dichlorophenoxyacetic acid activate different pathways. Plant Physiol. 137: 939-948.

Edy, A. 1998. Induksi embrio somatic dari eksplan poros embryo pada beberapa kultivar kacang tanah (Arachis hypogaea L.) secara in-vitro. MSc. Thesis, Bogor Agricultural University, Bogor, Indonesia.

Farooq, M., A. Wahid, N. Kobayashi, D. Fujita and S. M. A. Barsa. 2009. Plant drought stress: Effects, mechanisms and management. Agron. Sustain. Dev. 29: 153-188.

Fischer, R. A. and R. Maurer. 1978. Drought resistance in spring wheat cultivar. I. Grain yield response. Aust. J. Agric. Res. 29: 897-907.

Gaafar, R. M. and M. M. Saker. 2006. Monitoring of cultivars identity and genetic stability in strawberry varieties grown in Egypt. World J. Agric. Sci. 2: 29-36.

Gawande, N. D., D. G. Mahurkar, T. H. Rathod, S. W. Jahagidar and M. Shinde. 2005. In-vitro screening of wheat genotypes for drought tolerance. Ann. Plant Physiol. 19: 162-168.
Gopal, J. and K. Iwama. 2007. In-vitro screening of potato against water stress mediated through sorbitol and polyethylene glycol. Plant Cell Rep. 26: 693-700.

Jain, S. M. 1997. Creation of variability by mutation and tissue culture for improving plants. Acta Hortic. 447: 69-77.

Jain, S. M. 2001. Tissue culture-derived variation in crop improvement. Euphytica. 118: 153-166.

Kaeppler, S. M., R. L. Phillips and P. Olhoft. 1998. Molecular basis of heritable tissue culture-induced variation in plants. Current plant science and biotechnology in agriculture. In: Jain, S. M., B. S. Ahloowalia and R. E. Veilleux, editors. Somaclonal Variation and Induced Mutations in Crop Improvement. Vol. 32. Kluwer Academic Publisher, Dordrecht, Netherlands. pp. 465-484.

Kawasaki, T., T. Akiba and M. Moritsgu. 1983. Effects of high concentrations of sodium chloride and polyethylene glycol on the growth and ion absorption in plants. I. Water culture experiments in a green house. Plant Soil. 75: 75-85.

Kumar, P. S. and V. L. Mathur. 2004. Chromosomal instability in calli culture of Pisum sativum. Plant Cell Tiss. Cult. 78: 267-271.

Larkin, P. J. 1998. Introduction. In: Jain, S. M., D. S. Brar and B. S. Ahloowalia, editors. Somaclonal Variation and Induced Mutations in Crop Improvement. Kluwer Academic Publishers, Dordrecht. pp. 3-13.

Mahmood, I., A. Razzaq, M. Ashraf, I. A. Hafiz, S. Kaleem, A. Qayyum and M. Ahmad 2012a. In-vitro selection of tissue culture induced somaclonal variants of wheat for drought tolerance. J. Agric. Res. 50: 177-188.

Mahmood, I., A. Razzaq, I. A. Hafiz, S. Kaleem, A. A. Khan, A. Qayyum and M. Ahmad 2012b. Interaction of calli selection medium and stress duration for in-vitro selection of drought tolerant calli of wheat. Afr. J. Biotech. 11: 4000-4006.

Matheka, J. M., E. Magiri, A. O. Rasha and J. Machuka. 2008. In-vitro selection and characterization of drought tolerant somaclones of tropical maize (Zea mays L.). Biotechnology. 7: 641-650.

Mohamed, M. A. H., P. J. C. Harris and J. Henderson. 2000. In vitro selection and characterisation of a drought tolerant clone of Tagetes minuta. Plant Sci. 159: 213-222.

Mujib, A., S. Banerjee and P. Dev-Ghosh. 2007. Callus induction, somatic embryogenesis and chromosomal instability in tissue culture raised hippeastrum (Hippeastrum hybridum cv. United Nations). Propag. Ornam. Plants 7: 169-174.

Mundree, S. G., B. Baker, S. Mowla, S. Peters, S. Marais, C. V. Willigen, K. Govender, A. Maredza, S. Muyanga, J. M. Farrant and J. A. Thomson. 2002. Physiological and molecular insight into drought tolerance. Afr. J. Biotechnol. 1: 28-38.

Murashige, T. and F. Skoog. 1962. A revised medium for rapid growth and bioassays with tobacco tissue cultures. Physiol. Plant. 15: 473-497.

Naguib, N. A., E. A. I. Mohamed and Y. M. Abdel-Tawab. 2010. Laboratory evaluation of some barley genotypes under drought and salinity stresses. Plant Stress 4: 72-78.

Omidi, H. 2010. Changes of proline content and activity of antioxidative enzymes in two canola genotype under drought stress. Am. J. Plant Physiol. 5: 338-349.

Pontaroli, A. C. and E. L. Camadro. 2005. Somaclonal variation in Asparagus officinalis plants regenerated by organogenesis from long-term calli cultures. Genet. Mol. Biol. 28: 423-430.

Phutela, A., V. Jain, K. Dhawan and H. S. Nainawatee. 2000. Proline metabolism under water stress in the leaves and roots of Brassica juncea cultivars differing in drought tolerance. J. Plant Biochem. Biol. 9: 35-39. 
Rabert, G. A., P. Manivannan, R. Somasundaram and R. Panneerselvam. 2014. Triazole compounds alter the antioxidant and osmoprotectant status in drought stressed Helianthus annuus L. plants. Emirates J. Food Agric. 26(3): 265-276.

Rahayu, E. S., E. Guhardja, S. Ilyas and Sudarsono. 2005. Polietilena glikol (PEG) dalam media in-vitro menyebabkan kondisi cekaman yang menghambat tunas kacang tanah (Arachis hypogaea L.). Berkala Penelitian Hayati 11: 39-48.

Rahayu, E. S., S. Sudarsono. 2009a. Varian kualitatif kacang tanah hasil kultur in vitro dan seleksi in vitro. Biosaintifika. 1: 39-44.

Rahayu, E. S., S. Sudarsono. 2009b. Possible mechanisms of drought tolerance in peanut based on analysis of somaclonal lines derived from in vitro selection. In: Proceeding of the International Conference on Biological Science - Advances in Biological Sciences: Respect to Biodiversity from Molecular to Ecosystem for Better Human Prosperity. Publisher Faculty of Biology, Gadjah Mada University, Indonesia. p475-477.

Rai, M. K., R. K. Kalia, R. Singh, M. P. Gangola and A. K. Dhawan. 2011. Developing stress tolerant plants through in-vitro selection - An overview of the recent progress. Environ. Exp. Bot. 71: 89-98.

Riduan, A., H. Aswidinnoor, J. Koswara and Sudarsono. 2005. toleransi sejumlah kultivar kacang tanah terhadap cekaman kekeringan (Tolerance of Several Peanut Cultivars against Drought Stress). Hayati. 12: 28-34.

Rodrigues, P. H. V. 2008. Somaclonal variation in micropropagated Heliconia Bihai cv. lobster claw I plantlets (Heliconiaceae). Sci. Agric. (Piracicaba, Braz.) 65: 681-684.

Sakthivelu, G., M. K. Akitha-Devi, P. Giridhar, T. Rajasekharan, G. A. Ravishankar, T. Nede and G. Kosturkova. 2008. Droughtinduced alterations in growth, osmotic potential and in-vitro regeneration of soybean cultivars. Gen. Appl. Plant Physiol. 34: 103-112.

Sayar, R., H. Bchini, M. Mosbahi and M. Ezzine. 2010. Effects of salt and drought stresses on germination, emergence and seedling growth of durum wheat (Triticum durum Desf.). J. Agric. Res. 5: 2008-2016.

Serraj, R. and T. R. Sinclair. 2002. Osmolyte accumulation: Can it really help increase crop yield under drought conditions? Plant Cell Environ. 25: 333-342.

Shen, X., J. Chen, M. E. Kane and R. J. Henny. 2007. Assessment of somaclonal variation in Dieffenbachia plants regenerated through indirect shoot organogenesis. Plant Cell Tiss. Organ. Cult. 91: 21-27.

Shinde, B. M. and S. L. Laware. 2010. Effect of drought stress on agronomic and yield contributing characters in groundnut (Arachis hypogaea L.). Asian J. Exp. Biol. Sci. 1: 968-971.

Sinclair, T. R. 2011. Challenges in breeding for yield increase for drought. Trend Plant Sci. 16: 289-293.

Steuter, A. A. 1981. Water potential of aqueous polyethylene-glycol. Plant Physiol. 67: 64-67.

Sukamto, L. A. 2011. Effects of position and plant growth regulators on morphogenesis and growth rate of coconut endosperm invitro. Kasetsart J. (Nat. Sci.) 45: 977-984.

Sulichantini, E. D. S. 1998. Induksi embrio dari eksplan poros embrio dan embryonic leaflet pada beberapa kacang tanah (Arachis hypogaea L.) komersial di Indonesia. MSc. Thesis. Bogor Agricultural University, Bogor, Indonesia.

Tremblay, L., C. Levasseur and F. M. Tremblay. 1999. Frequency of somaclonal variation in plants of black spruce (Picea mariana, Pinaceae) and white spruce ( $P$. glauca, Pinaceae) derived from somatic embyogenesis and identification of some factors involved in genetic instability. Am. J. Bot. 86: 1373-1381.

Valledor, L., R. Hasbu'n, M. Meijo'n, J. L. Rodrı'guez, E. Santamarı'a, M. Viejo, M. Berdasco, I. Feito, M. F. Fraga, M. J. Can ${ }^{\sim}$ al and R. Rodrı'guez. 2007. Involvement of DNA methylation in tree development and micropropagation. Plant Cell Tiss. Organ. Cult. 91: 75-86.

Vorasoot, N., P. Songsri, C. Akkasaeng, S. Jogloy and A. Patanothai. 2003. Effect of water stress on yield and agronomic characters of peanut (Arachis hypogaea L.). Songklanakarin J. Sci. Technol. 25: 283-288.

Wagih, M. E., A. Ala and Y. Musa. 2004. Regeneration and evaluation of sugarcane somaclonal variants for drought tolerance. Sugar Tech. 6: 35-40.

Wani, S. H., P. A. Sofi, S. S. Gosal and N. B. Singh. 2010. In-vitro screening of rice (Oryza sativa L.) calli for drought tolerance. Commun. Biomet. Crop Sci. 5: 108-115.

Widoretno, W., R. Megia and Sudarsono. 2003. Respons embrio somatik terhadap polietilena glikol dan penggunaannya untuk seleksi in-vitro terhadap stres kekeringan. Hayati 10: 134-139.

Widoretno, W. and Sudarsono. 2004. Evaluasi sejumlah galur kedelai varian somaklonal hasil seleksi in-vitro terhadap stress kekeringan. Hayati. 11: 11-20. 